\title{
EL SINDICALISMO Y EL ACCESO AL DECISOR EN ARGENTINA. LA REFORMA PREVISIONAL DURANTE LA DECADA DE 1990*
}

\author{
Eduardo Araya M. \\ Universidad de Chile \\ Diego Barría T. \\ Universidad de Chile \\ Oscar Drouillas C. \\ Capacita
}

\section{Resumen}

Dentro de las reformas previsionales llevadas a cabo en Latinoamérica, el caso de Argentina presenta uno de los más bajos niveles de privatización. Ello ocurrió en un contexto de negociación entre el gobierno de Carlos Menem y la Confederación General del Trabajo (CGT). En esta nota de investigación se intenta dar un marco interpretativo que permita explicar las posibilidades de influir en el proceso de reforma previsional por parte del sindicalismo argentino. Se argumenta que la CGT fue capaz de influir en la formulación de la reforma previsional debido a su fortaleza política, basada en una relación de larga data con el Partido Justicialista. Además, ello ocurrió, gracias a que el sindicalismo mostró una significativa capacidad de hacer uso de sus recursos político.

Palabras Claves: Sistema Previsional Argentino, Reforma Previsional, Recursos Políticos, Sindicalismo

\section{Abstact}

Among the pension system reforms implemented in Latin America since 1981, Argentina stands out as having a less pro-privatization bias, where this result can be explained by the context of negotiation between the Carlos Menem government and General Work Confederation (CGT). The paper is intends to provide a suitable analytical explanation to examine the union's real chance of having a real influence in the reform being analyzed. It is hypothesized that the CGT was able to influence the formulation of the pension system reform by taking advantage of its political strength, which hinges upon a long lasting relation with the "Justicialista" political party. On top of this, this research argues that the unions demonstrated significant capacity to make use of these political assets.

Keywords: Argentinean Pensions System, Pensions System Reform, Political Recourses, Unionism.

* Este trabajo forma parte de un proyecto financiado por la Confederación Francesa Democrática de Trabajadores y el Instituto de Asuntos Públicos de la Universidad de Chile. 


\section{Introducción}

Durante 1990, Latinoamérica fue testigo de varias reformas de los sistemas de pensiones existentes en las décadas anteriores. De distinto tipo, dependiendo del país, éstas establecieron, con distintas intensidades, algún tipo de mutación desde sistemas previsionales públicos a nuevos esquemas en los que se incorporaban mecanismos de participación privada ${ }^{1}$.

Mesa-Lago (2001: 69-70) ha identificado tres tipos de reformas: sustitutivas, paralelas y mixtas. En las reformas sustitutivas se cambió un sistema público por el privado, no siendo permitida tras la reforma la incorporación de nuevos miembros al primero. Las reformas paralelas, en tanto, llevadas a cabo en Perú y Colombia, reformaron el sistema público y crearon un sistema privado. Éstos compiten entre si por la captación de afiliados. Por último, las reformas mixtas, implementadas en Argentina y Uruguay, mantienen un sistema público que entrega pensiones mínimas, el que se integra con un sistema privado que entrega pensiones complementarias.

El paradigma previsional chileno fue levantado como el modelo a seguir, por parte del Banco Mundial, junto al Banco Interamericano de Desarrollo y el Fondo Monetario Internacional, desde 1994 en el informe "Adverting the old age crisis". No obstante, éste se implementó en medio de una dictadura ${ }^{2}$. En un inicio, se pensaba que este tipo de reformas solamente podrían llevarse a cabo en un contexto no democrático, pero la aceptación de la Concertación del sistema previsional habría legitimado la opción de impulsar este tipo de reformas (MesaLago, 1999: 134-5). Esta actitud habría permitido que en el informe de 1994, y en uno posterior - del año 2004- que matizaba las opiniones y las estrategias a seguir, el Banco Mundial intentara demostrar las bondades que traería el paso desde un sistema previsional público a uno privado.

En torno al nuevo sistema previsional se crearon una serie de supuestos que planteaban que el sistema privado era mejor que el público, por lo que se aumentaría el número de afiliados; que éstos serían más regulares en sus pagos, pues de ello dependería su pensión;

1 La literatura sobre reformas previsionales en Latinoamérica ha tendido a distinguir entre dos tipos de sistemas: público y privado. Los sistemas públicos se caracterizan por: la existencia de contribuciones no definidas; beneficios definidos por la ley, estableciendo mínimos y máximos de las pensiones y con formulas de cálculo de pensiones especificadas; régimen de financiamiento de capitalización parcial colectiva y; una administración pública del sistema. Por su parte, los sistemas privados se caracterizan por: definir un nivel de contribución por parte del trabajador; no define beneficios, siendo éstos inciertos y en base a lo acumulado en la cuenta personal: régimen de financiamiento basado completamente en los aportes individuales y; administración privada del sistema, aunque puede ser pública, privada o mixta (Mesa-Lago, 2001: 68).

2 Ello no implicó que ciertos actores no intentaran oponerse a la reforma. En particular, el Comandante en Jefe de la Fach, General Leigh, hacia 1974 se opuso a la reforma provisional, siendo, con posterioridad, sacado por Pinochet de la Junta (Castiglioni, 2001: 55-57). 
que la competencia entre administradoras mejoraría la eficiencia de éstas, disminuyendo los costos y aumentando los beneficios provisionales; que se reducirían los costos fiscales de largo plazo; que se aumentaría el ahorro nacional y que se aumentaría, además, el retorno real de las inversiones; que se diversificaría el portafolio de las inversiones, preferentemente concentrado en la deuda pública (Mesa-Lago, 2001). Estas promesas, no todas cumplidas, se expandieron ampliamente en el continente.

Madrid (2005) sugiere que más allá de las presiones fiscales existentes, la influencia de las ideas propagadas por el Banco Mundial y redes de policymakers latinoamericanos, donde se compartía experiencia en torno a la reforma chilena, habría sido fundamental para la adopción de este ideario de reformas, basado en la experiencia chilena. La capacidad de influir del Banco Mundial, además de la tendencia de los policymakers de mirar experiencias cercanas, como la chilena, habrían permitido la adopción de este modelo privatizador de reformas.

Algunos autores han sostenido que las reformas de mercado son más fáciles de ser implementadas en países con crisis fiscales recientes, con apoyo material externo a favor de esas reformas, con policymakers aislados en el Ejecutivo. Además, estos países deberían contar con una elite y una masa que apoya las reformas. El apoyo externo y el aislamiento al tomar las decisiones no serían condiciones suficientes para implementar las reformas. Por el contrario, para ser viables, ellas deberían ser apoyadas por los sectores favorecidos anteriormente bajo el modelo ISI, además del resto de la población (Armijo y Faucher, 2002).

Armijo y Faucher (2002) sostienen que las reformas más exitosas han sido diseñadas localmente. En la misma línea, Weyland (2006) ha planteado que en países con gran dependencia de la ayuda de las Instituciones Financieras Internacionales (IFI), como Brasil y Costa Rica, las autoridades locales han podido oponerse a la implementación de reformas previsionales, como las impulsadas por estas instituciones.

Mesa-Lago (1999), por otro lado, ha mostrado que existe una relación inversa entre grado de democracia de países y el nivel de privatización de las reformas provisionales. Utilizando índices de democracia de Freedom House para el año de la reforma provisional y el grado de privatización de éstas, plantea que gobiernos menos democráticos impulsan reformas más privatizadoras y que los más democráticos impulsan reformas que establecen sistemas previsionales más públicos.

En Chile, donde existían los índices más bajos de democracia (y de posibilidad de participar) se dio la reforma más privatizadora. En cambio, en Argentina los altos niveles de democracia dieron como resultado una reforma de bajo nivel de privatización. 
TABLA 1: Relación entre grados de democratización y privatización en la reforma de pensiones en América Latina

\begin{tabular}{|l|c|c|c|c|}
\hline \multicolumn{5}{|c|}{ GRADO DEMOCRATIZACIÓN EN EL AÑO DE LA REFORMA } \\
\hline Países & Año Reforma & Marcas & Orden & Grado de sistema público v/s privado \\
\hline Costa Rica & $1995-98$ & 1,5 & 1 & 1 \\
\hline Uruguay & 1995 & 2,0 & 2 & 2 \\
\hline Argentina & 1993 & 2,5 & 3 & 2 \\
\hline Bolivia & 1996 & 2,5 & 3 & 7 \\
\hline El Salvador & 1996 & 2,5 & 3 & 4 \\
\hline Colombia & 1993 & 3,0 & 5 & 6 \\
\hline México & $1995-6$ & 4,0 & 6 & 5 \\
\hline Perú & 1992 & 5,5 & 7 & 9 \\
\hline Chile & $1979-80$ & 6,0 & 9 & 7 \\
\hline $\begin{array}{l}\text { Marcas y Orden están ordenados de menor (más democrático) a mayor (menos democrático). El Grado sistema público } \\
\text { v/s privado implica que el 1 es el más público (menos privado) y el } 9 \text { el menos público (más privado) }\end{array}$ \\
\hline
\end{tabular}

Fuente: Mesa-Lago (1999:136).

Ello plantea una serie de preguntas. Si la influencia de las IFI es relativa, como sugiere Weyland (2006) y existe una relación inversa entre niveles de democracia y alcances privatizadores de las reformas previsionales, entonces pareciera que los resultados sobre el nuevo tipo de reforma previsional se definen en la arena política interna.

Para el caso argentino cabe la pregunta si el sindicalismo influyó en que se llevara adelante una reforma poco privatizadora. Durante la última década ha surgido una serie de estudios (Etchemedy y Palermo, 1998, Etchemedy, 2001, Murillo, 2001, Norman, 2001) que plantean que las reformas económicas en Argentina no fueron implementadas por un Presidente con capacidad de veto, junto a policymakers aislados.

Al contrario de lo que estas visiones plantean, estos estudios reconocen una serie de actores más que actúan en estos procesos. Por ejemplo, en materia de reformas previsionales, dentro del Estado, las burocracias previsionales y los equipos económicos también tuvieron incidencia en los cambios llevados adelante. La primera, intentaría proyectos incrementales, los que podría lograr si es un actor fuerte. En cambio, los segundos, buscarían reformas más radicales (Coelho, 2002: 45-47).

Esta variedad de actores ha llevado a que las reformas hayan sido interpretadas como el fruto de un proceso de construcción de coaliciones que le dieron sustento y viabilidad política. Por ejemplo, en materia laboral y de obras sociales, Menem no impuso su voluntad y, al final, buscó, aprobar, "la reforma posible" (Etchemedy y Palermo, 1998: 581).

Etchemedy (2001) plantea que las reformas de mercado no fueron impuestas unilateralmente por el Presidente, sino que se sustentan en coaliciones negociadas. La economía argentina, 
desde la década de 1940, estableció incentivos para ciertos actores. Las coaliciones que sustentaron las reformas estaban conformadas por esos actores, a los que se les mantuvieron rentas en este nuevo modelo económico. El autor plantea que el Estado, al formular reformas, moldea preferencias de actores sociales.

Norman (2001) sostiene que las reformas impulsadas en Argentina, entre 1989 y 1998, mostraron que las instituciones estatales son más abiertas de lo que se ha reconocido en la literatura institucionalista. En especial, plantea que las reformas económicas impulsadas por Menem abrieron nuevas oportunidades para la participación, haciendo el proceso de formulación de las políticas más abierto. Ello se produjo una vez que el gobierno impulsó la búsqueda de consenso, tras la obstrucción que en el parlamento la Confederación General del Trabajo (CGT) dio a las iniciativas de reformas laborales. En su opinión, la transformación económica no hubiese sido posible sin un presidente fuerte, pero, a través del proceso de reformas, Menem debió responder a las demandas de actores estatales y no estatales (Norman, 2001: 195).

En esta nota de investigación se intenta dar un marco interpretativo que permita explicar las posibilidades de influir en el proceso de reforma previsional por parte del sindicalismo argentino, el que se basa en la forma en que los actores utilizan sus recursos políticos. Además, propone una escala de medición de la influencia que los actores sociales pueden tener en los procesos de formulación de políticas públicas, la que es utilizada en las conclusiones.

El análisis se basa solamente en la CGT. Se excluye a la Central de Trabajadores de Argentina (CTA) debido a que, durante el período, optó por una estrategia de resistencia (Murillo, 1997), restándose de intentar participar en la formulación de política.

El sindicalismo argentino es, según Zapata (1993), de tipo populista. Las principales características de esta configuración sindical son la separación de las dirigencias de las bases y su cercanía con las autoridades gubernamentales. Los dirigentes de los sindicatos populistas tienen, incluso, lugares dentro de la institucionalidad laboral o social estatal.

Los recursos políticos varían entre los sindicalismos pluralistas y corporativistas ${ }^{3}$. En el caso del pluralismo, la capacidad de movilización, el número de afiliados, la concentración espacial son de importancia, mientras que en el caso de los sindicalismos corporativistas los recursos importantes son los propios de las organizaciones y los sistemas de intermediación de intereses en los que se insertan (Da Silva, 2006: 345).

3 El sindicalismo populista, al que hace referencia Zapata (1993), es asimilable al corporativista, mencionado por Da Silva (2006). 
En esta nota se plantea que el sindicalismo argentino fue capaz de utilizar sus recursos políticos de manera tal que pudo convertirse en un actor con capacidad de veto de las reformas económicas de Menem. Esta no es una característica del sindicalismo de la década de 1990; por el contrario, corresponde a una tradición histórica de una actitud negociadora, que le ha permitido a la CGT acceder, sin importar que sus opositores estuvieran en la Casa Rosada, a los decisores de políticas públicas.

El segundo apartado presenta un marco conceptual que intenta identificar los recursos políticos con los que el sindicalismo cuenta para poder influir en las decisiones de gobierno. El tercero analiza si el sindicalismo argentino cuenta con dichos recursos y cómo los utiliza. El cuarto describe cómo el sindicalismo logró cambiar el proyecto previsional que Menem, en un inicio, intentó llevar adelante. Finalmente se presentan algunas conclusiones.

\section{Recursos políticos y la influencia de los actores en las decisiones políticas. Las posibilidades sindicales}

En un sistema político, la capacidad de influencia que tendrá un actor determinado depende de los recursos políticos. Éstos son medios con los que un sujeto puede lograr influir en las conductas de otros actores. Sin embargo, la sola tenencia de recursos no asegura influencia, pues existen diferencias en la forma en que se distribuyen en la sociedad, en la medida en que son usados y en la pericia con que emplean. Los sujetos cuentan con diversas capacidades para transformar condiciones, hechos o circunstancias en recursos políticos. La pericia, o sea, la medida en que los recursos son empleados para influir, provoca distintas intensidades de influencia y poder de los grupos y las personas (Dahl, 1985: 48-51).

Pasquino (1989) sugiere que los grupos intentan aumentar sus posibilidades de éxito utilizando los recursos, a los que tienen acceso más expedito y los canales de comunicación y presión sobre el poder político que le resultan mas fáciles de usar. Igualmente, los grupos tratan de identificar los niveles y las instancias de toma de decisión a las cuáles deben apuntar su acción de presión.

Existen cinco recursos que determinan la posibilidad de éxito de un grupo actuando sobre el mecanismo del poder político para obtener sus intereses (Pasquino, 1989). El primero es la dimensión, en términos de adherentes, con los que cuenta un grupo. Ella puede ser uno de los recursos más significativos, tanto por la influencia que puede ejercer en resultados electorales como por la posibilidad de amenazar la estabilidad o ámbitos de gobernabilidad.

En segunda instancia, se encuentra la representatividad que tiene el grupo. En la medida que un grupo es capaz de agregar las actividades de un colectivo, y actuar en su nombre, 
aumentan sus posibilidades de ser considerado, a lo menos potencialmente, en los procesos de toma de decisiones, lo que, finalmente, dependerá de la permeabilidad o sensibilidad de los ámbitos del poder.

Un tercer tipo de recurso es el dinero, el que determina capacidades de acción como, por ejemplo, la realización de campañas públicas, además de la posibilidad de lograr acceso a contratar apoyos técnicos. Este punto se relaciona con la importancia de un cuarto recurso: la capacidad para articular propuestas. Esta cuestión es crucial pues, en la medida que sea un recurso en manos de un grupo, le permite traspasar el rechazo o apoyo de ciertas medidas, siendo capaz de presentar alternativas a las opciones existentes en los procesos decisionales.

Por último, la ubicación que un actor o grupo ocupa en el proceso productivo o en el sistema político de un país es un recurso político que determinará las posibilidades para poder influir en los procesos de decisión. Para Pasquino, fundamental es la capacidad que estos grupos tengan de cuestionar las acciones gubernamentales y generar malestar de los ciudadanos hacia el gobierno.

Dependiendo de los tipos de recursos con que cuentan, y los usos que hacen de ellos, ciertos actores pueden tener un lugar privilegiado en los procesos de decisiones gubernamentales, aun cuando no sean parte del gobierno ni de otros espacios de decisión, como el parlamento. Deutsch (1976) reconoce que dentro de los sistemas políticos existen estratos relevantes que influyen en la toma de decisiones, los que son reconocibles porque deben ser tomados en cuenta, al tomar una decisión, para evitar que una política se vuelva completamente irrealizable o para que la política nacional no se transforme en un desastre.

Deutsch (1976) plantea que, en el campo político, la eficacia se refiere a la capacidad de lograr que un resultado improbable aumente sus posibilidades de ocurrencia. En base a eso, se puede argumentar que la posibilidad de convertirse en actor con capacidad de veto podría estar determinada por la tenencia y utilización eficiente y eficaz de recursos políticos, lo que lo transforma a u individuo en un actor relevante.

Este concepto de Deutsch se relaciona con el de "veto player" (Tsebelis 1995, 1999) o actor con capacidad de veto; un sujeto, individual o colectivo, del cual se requiere su acuerdo para poder impulsar algún cambio de política. Los "veto players" a los cuáles se refieren los estudios de Tsebelis son de tipo institucional, como el Jefe de Gobierno o los partidos políticos en coaliciones de gobierno o en el parlamento. El autor plantea que a mayor distancia ideológica entre actores y a un mayor número de éstos, la posibilidad de articular un cambio de política decrecen, aumentando la estabilidad de las políticas (Tsebelis, 1995). 
El sindicalismo, en tanto organización de intereses de un grupo social (trabajadores), busca mejorar las condiciones y perspectivas económicas y sociales de sus representados. Barría (1971) sostiene que el sindicalismo representa los intereses cotidianos de los trabajadores en sus puestos de trabajo, y busca representar las opiniones colectivas de sus integrantes. No obstante, el sindicalismo sería solo una parte del movimiento obrero, conformado además por los partidos políticos, cooperativistas, juntas de pobladores, los que engloban la actuación social de la clase trabajadora de un país. En este trabajo se hace énfasis en las características reivindicativas del sindicalismo, por sobre los proyectos políticos que pueda proponer.

Los sindicalismos tienen, además, dos características. En primer lugar, al ser reivindicacionistas de derechos, esperan que sus demandas sean consideradas por la autoridad y se transformen en políticas y legislaciones. En Latinoamérica, los sindicatos se han organizado, históricamente, para defender los intereses de sus afiliados, por medio de la acción colectiva - negociaciones colectivas, huelgas-, estrategias políticas - presiones, huelgas generales-y servicios sociales -cooperativas, seguro médico, jubilación - y han sido tradicionalmente participantes activos y decisivos en el proceso de formulación de políticas públicas (BID, 2006).

En segundo lugar, el sindicalismo es un actor que actúa en nombre de los trabajadores, aun cuando no tenga el apoyo de las bases. Ello se logra, por ejemplo, a través del aseguramiento que la legislación haga de la capacidad sindical de representar a los trabajadores, como ocurre en Argentina.

En la literatura de las últimas dos décadas se han identificado una serie de recursos políticos con los que los sindicatos cuentan para influir en la arena política. Victoria Murillo $(2000,2001)$ ha intentado explicar las actitudes de los sindicatos argentinos, mexicanos y venezolanos frente a las reformas de mercado ocurridas en la década de 1990, a partir de tipos de relaciones que éstos establecen con el gobierno reformador (a los cuales adhieren) Según ella, los gobiernos pueden aceptar o rechazar las demandas de los sindicatos, mientras que los sindicatos pueden contenerse o movilizarse en la búsqueda de respuesta a las demandas.

En este escenario, la actitud de los dirigentes sindicales se basa en dos supuestos. En primer lugar, la intención de mantener su liderazgo los lleva a aliarse con dirigentes políticos de partidos de base de apoyo sindical. Cuando sus aliados están en el poder, los dirigentes sindicales llevan estrategias de contención. En segundo lugar, cuando sus aliados políticos están en la oposición, se movilizan. 
El pertenecer al mismo partido, facilita la comunicación entre gobierno y sindicatos, haciendo que el segundo confié en el gobierno y no deba demostrar su deseo de ceder en sus posturas. Estudios tienden a predecir que cuando partidos de apoyo sindical están en el gobierno, los sindicatos restringen sus movilizaciones (Murillo, 2001: 7) para mantener los vínculos políticos para obtener respuestas a sus demandas. Además, apoyan las reformas, a pesar de la incertidumbre que ellas traen (Murillo, 2001: 17) y posponen los conflictos industriales para poder tener acceso al Estado (Murillo, 1997: 422). Esta actitud sindical busca preservar las relaciones con el gobierno hacia el futuro (Murillo, 2001: 198).

Otras variables a considerar por la teoría de Murillo son la competencia partidaria por el liderazgo y la competencia sindical. La competencia por el liderazgo de los dirigentes sindicales de distintos partidos incide en la actitud que estos toman. En la medida que no existen competidores de otros partidos, los dirigentes pueden tener actitudes de contención. En cambio, de existir competencia, pueden preferir actitudes movilizadoras.

La competencia sindical también incide en la relación con los gobiernos. En la medida que existe más de un sindicato, el gobierno puede mostrarse menos dispuesto a negociar con ellos. De igual manera, dirigentes sindicales que tienen sindicatos competidores, pierden parte de su capacidad para movilizar trabajadores. En este esquema tanto las relaciones con el gobierno, al que apoyan, y la unidad organizativa son recursos políticos valiosos, ya que en situaciones en que los dos están presentes, los sindicatos lograr tener éxitos al intentar influir en las decisiones que los gobiernos toman.

Valenzuela (1991) identifica una serie de factores que explican la forma en que los movimientos laborales se insertan en los sistemas político, como: la consolidación organizacional de los sindicalismos; la unidad o fragmentación del movimiento laboral; la relación entre los partidos y los sindicatos y; los efectos de los diferentes regímenes políticos en la relación partido sindicatos

La consolidación organizacional depende de la obtención de la confianza de los trabajadores, el desarrollo de redes sindicales de carácter nacional, el nivel de penetración a nivel de planta y el reconocimiento del Estado. La unidad o fragmentación del movimiento está relacionada con varios factores. Por ejemplo, puede existir más de una central nacional, debido a que representan distintos grupos de trabajadores, o debido a la competencia entre dirigentes por representar a los trabajadores. Otra razón de la fragmentación puede ser la diferencia ideológica entre sectores de trabajadores.

La relación entre los partidos y los sindicatos se presenta por la necesidad de los sindicatos de obtener apoyo de partidos para alcanzar sus demandas. Ella depende de dos factores. 
En primer lugar, el grupo al que quiere representar el partido. Partidos que buscan representar sectores más amplios inciden en una inserción débil del sindicato, a diferencia de partidos que buscan representar sectores más específicos, en los que existe una relación más cerrada del sindicato y los partidos, siendo los dirigentes sindicales parte de la dirigencia partidaria.

En segundo lugar, el momento de nacimiento del partido o el sindicato incide en sus relaciones. Sindicatos que nacen largo tiempo después del partido con el que se relacionan suelen ser más débiles que los que nacen antes. Lo mismo ocurre con partidos que se relacionan con sindicatos de largo tiempo. Partidos recién nacidos, pueden, a su vez, ayudar a conformar sindicatos entre sus militantes.

En los regímenes democráticos, la relación entre sindicatos y partidos depende de la posición del último. Cuando está en el gobierno un partido, o una coalición de partidos obreros, no puede implementar un programa de gobierno que deje totalmente satisfecho a los sindicatos. El partido hace subordinar los intereses sindicales a los del gobierno. En los regímenes autoritarios, los sindicatos no necesariamente pierden su posibilidad de llevar demandas al gobierno. Gobiernos autoritarios abiertos pueden permitir que algunos dirigentes sindicales puedan acomodarse al régimen, a diferencia de los regímenes autoritarios que reprimen a los sindicatos y sectores sociales, donde se debe establecer una estrategia de oposición (Valenzuela, 1991).

En un reciente informe, el BID (2006) también identifica a las alianzas políticas como un recurso que permite a los sindicatos influir en la formulación de políticas públicas. A ello, se agregan las capacidades de negociación con las que las organizaciones de trabajadores cuentan. Para el organismo internacional, los sindicatos, ahora, tienen menos peso que antes en el proceso de formulación de políticas pública, pero aun influyen, especialmente, si el partido que está en el poder busca representar a los trabajadores, si logran movilizar a los empleados del sector público, y si pueden forjar alianzas más amplias con los consumidores 0 aliados transnacionales.

En un contexto neoliberal, los sindicatos tienden más a invertir sus recursos en resistir la adopción de políticas de gran alcance con efectos intensos en sus afiliados. Así, por ejemplo, los sindicatos se movilizan en oposición a la reforma de la legislación laboral, que es una política de amplio alcance - afecta a todos los afiliados - y gran intensidad - afecta a la seguridad de los trabajadores y su remuneración -, antes que por reivindicaciones corporativas o particulares (BID, 2006).

Para el interés de este trabajo, la capacidad de influir con que cuenten los sindicatos en los procesos de diseño e implementación de políticas públicas, hace referencia a la posibilidad 
que tienen de agregar, matizar o eliminar contenidos de política, amoldándolos, en algún nivel, a sus intereses 0 , incluso, paralizando o cambiando la política por otra.

El éxito de la influencia de los sindicatos en el proceso de formulación de políticas públicas depende del costo que tenga para el gobierno hacer concesiones en cada campo, de los grupos beneficiarios de cada reforma y de la importancia que tengan esos grupos para el gobierno. Desde otra perspectiva, esto muestra que la decisión gubernamental está influida por la fuerza con que el sindicato cuente para hacer de su demanda una cuestión de alcance nacional. Si eso no es posible, en esa misma lógica, la reivindicación o demanda no tendrá buen resultado (BID, 2006).

Los sindicatos, al intentan influir en la formulación de políticas, tienen dos opciones. En primer lugar, intentar participar en el proceso como un actor que influye en la elección de las opciones tomadas por el decisor (o convertirse en él). Esto no implica ni un apoyo ni un rechazo a los proyectos de políticas de las autoridades, pero si una actitud positiva hacia la participación. Una segunda opción sindical es la de rechazar la política en discusión, o, incluso, la sola opción de discutir algún proyecto en la materia. Ello implica una actitud negativa hacia la participación.

Los resultados que los sindicatos obtengan de las opciones que realicen depende de los recursos que tengan a su disposición, y de la capacidad para utilizarlos. En especial, las relaciones con los partidos políticos, las capacidades organizativas y la unidad o fragmentación sindical (Murillo 2000, 2001, Valenzuela, 1991, BID, 2006) son los puntos críticos que explican que el sindicalismo tenga opciones de poder influir en las decisiones de políticas públicas.

La actitud positiva a la participación de los sindicatos en busca de lograr formular una política pública puede ser identificada por dos características: a) el sindicato participa de la discusión de la política en un espacio abierto por la autoridad con la potestad para formular política; b) el sindicato tiene la intención de hacer propuestas que sean consideradas en la política.

Para poder participar en la formulación de la política, un actor debiera contar con ciertos recursos políticos. En primer lugar, debiera tener una ubicación importante en el sistema política. La importancia estaría dada por el hecho de que la acción del actor puede tener implicancias en las posibilidades de impulsar una política (Deutsch, 1976). En segunda instancia, el actor debe contar con una serie de contactos con partidos políticos, además de tener la posibilidad de acceder al decisor. Estas dos cuestiones aumentan la posibilidad de ser incorporado en las discusiones. Por último, el actor debe tener la capacidad de articular propuestas pues, de no ser así, su participación en una instancia que formulará políticas se limitaría a aprobar o rechazar propuestas ajenas. 
La participación, sin embargo, no asegura la obtención de resultados para los sindicatos. Aquí, proponemos una escala que puede ser de utilidad para medir el grado de éxito de la inserción sindical en la formulación de políticas. El primer nivel grafica una situación en la que el sindicato no logra influir bajo ninguna forma en la política, en tanto el último muestra a un sindicato que es quién "hace la política", es decir, logra cooptar al decisor.

1. Sindicato no es considerado en el proceso de formulación. No participa de ninguna forma.

2. Sindicato es parte de los actores que son consultados por los decisores de políticas, pero sus contenidos no son considerados.

3. Sindicato es consultado por los decisores y sus contenidos, junto a los de otros actores, son considerados e incorporados de manera parcial, junto a lo de otros actores consultados.

4. Sindicato participa como un actor con capacidad de veto dentro del proceso de formulación. Es capaz de vetar contenidos de otros actores y logra que el decisor incorpore solamente contenidos propuestos por él.

5. Sindicato logra cooptar al decisor y logra que apruebe la política sindical.

Existen dos variables que permiten clasificar casos. La primera, es la incorporación de los sindicatos a los espacios de decisión. Esta variable determina en qué medida el sindicato tiene acceso a los espacios de decisión de política. Existen varios indicadores para medir esta variable, por ejemplo, la participación o no del sindicato en mesas de negociación o comisiones de trabajo.

La segunda variable se refiere al grado de incorporación de los contenidos de las propuestas sindicales en lo que finalmente será la política. Para medir esta variable debiera identificarse los principios, de corresponder, que buscan salvaguardar los sindicatos en sus propuestas; los objetivos que buscan las propuestas sindicales; las medidas que proponen para conseguir la materialización de principios y objetivos. Una vez identificadas estas cuestiones se debiera ver en la política formulada si fueron incorporadas o no.

Una actitud negativa a la participación de los sindicatos en la formulación de políticas, los coloca fuera de los espacios de participación abiertos por la autoridad. A través del rechazo, desde fuera, las organizaciones sindicales buscan inhibir al decisor político de formular una política pública con ciertas características o boicotear algunos de sus contenidos. Casos como estos se caracterízan por: a) la existencia de un sindicato que, expresamente, manifiesta no querer participar en los espacios de discusión; b) la presencia de una actuación sindical que busca lograr que el decisor se inhiba de formular políticas en una materia. 
Para poder tomar esta forma, y tener éxito, un actor debe tener una ubicación importante en el sistema político, de manera que su negativa sea considerada por los decisores. En segunda instancia, el actor debe poder arrogarse la representatividad del colectivo al nombre del cual actúa. No interesa tanto si es ella es legitima (reconocida por ese colectivo) sino que sea reconocida por el decisor. En la medida que éste crea que ese actor logra actuar a nombre del colectivo, tendrá más incentivos para considerar sus posiciones. En tercer lugar, el actor debe contar con una unidad organizativa. Esta cuestión es fundamental pues en la medida que menos organizaciones existan compitiendo por actuar a nombre de un colectivo, aumentan las posibilidades de ser considerado el representante de él, siendo la unidad, la situación ideal para los grupos que esperan representar a alguien. Por último, para poder tener una actitud negativa a la participación, los actores deben tener la capacidad de desarrollar movilizaciones en las que puedan plantear sus puntos de vistas y demostrar su fuerza dentro de la sociedad.

Un sindicato que fracasa en sus objetivos, no logra inhibir al decisor. Sin embargo, de ser exitoso, el sindicato logra truncar la política.

1. Sindicato se manifiesta contrario a la política pública, pero no logra articular ninguna acción de resistencia.

2. Sindicato es capaz de establecer algún tipo de acción de resistencia a la política, pero su rechazo no es considerado por el decisor.

3. Sindicato logra que el decisor reconozca expresamente el rechazo a la política y al sindicato como actor, pero ello no implica un cambio en los contenidos de la formulación.

4. Sindicato a través de su acción de resistencia logra conformarse como un actor con capacidad de veto, siendo capaz de inhibir al decisor de avanzar en puntos resistidos por el sindicato.

5. Sindicato logra boicotear la política, paralizando el proceso de formulación.

Existen dos variables que permiten clasificar los casos en esta escala. La primera es la capacidad de articular una resistencia visible en la opinión pública a la discusión de política. Esta variable se puede medir con ciertos indicadores como la existencia o no de acciones como, por ejemplo, marchas, huelgas, paralizaciones de caminos, toma de propiedad pública o privada, y la frecuencia con que ocurren y; la existencia de manifestaciones de apoyo de actores políticos o sociales, que den cuenta de que la actitud de resistencia es conocida por la opinión pública y el decisor.

Una segunda variable se refiere a la capacidad de eliminar contenidos de la política. Para medir esta cuestión se debiese identificar qué contenidos fueron eliminados debido a la acción 
sindical de resistencia. En caso de truncarse la política, se debiera encontrar suficiente evidencia que deje de manifiesto cómo la acción sindical explica dicha determinación.

TABLA 2: Actitudes positiva y negativa hacia la participación en la formulación de políticas públicas

\begin{tabular}{|c|c|c|}
\hline $\begin{array}{l}\text { Actitud hacia la participación en } \\
\text { la formulación de políticas }\end{array}$ & Variables & Recursos Políticos \\
\hline Positiva & $\begin{array}{l}\text { - Incorporación del actor al } \\
\text { espacio de decisión de } \\
\text { política. } \\
\text { - Incorporación de intereses } \\
\text { en el proyecto de gobierno }\end{array}$ & $\begin{array}{l}\text { - Ubicación importante en el } \\
\text { sistema político } \\
\text { - Relación con partidos } \\
\text { - Acceso al decisor } \\
\text { - Capacidad de articular propuestas }\end{array}$ \\
\hline Negativa & $\begin{array}{l}\text { Articulación de resistencia } \\
\text { visibles al proyecto de } \\
\text { gobierno } \\
\text { Eliminación de contenidos } \\
\text { del proyecto de gobierno }\end{array}$ & $\begin{array}{l}\text { - Ubicación importante en el } \\
\text { sistema político } \\
\text { - Representatividad } \\
\text { - Unidad organizativa } \\
\text { - Capacidad de movilización }\end{array}$ \\
\hline
\end{tabular}

Fuente: Elaboración propia.

Estas dos opciones, en todo caso, no son excluyentes entre sí. No resultaría extraño, por ejemplo, que actores, que buscan influir en procesos de formulación de políticas públicas, utilicen, simultáneamente, ambas opciones para conseguir sus objetivos. Otra opción es que actores, ante escenarios adversos, y en los que no tienen control de los temas a discutir, sigan una actitud negativa a la participación, buscando truncar la formulación de políticas y vetar ciertos contenidos para transformar el escenario a otro nuevo en el que tengan posibilidades de controlar los temas a discutir y, así, incorporarse positivamente, y de manera más conveniente a la formulación de políticas públicas.

\section{El sindicalismo argentino y el uso de sus recursos políticos}

Durante la década de 1990, la CGT se dividió a causa de las diferentes miradas que los sectores sindicales tenían con respecto a las políicas económicas llevadas por el gobierno de Carlos Menem. En 1989 una parte del sindicalismo se proclamó menemista (CGT San Martín), mientras que otro sector se mostró opositor (CGT Azopardo). La CGT intentó reunificarse en 1990, incluso con la intervención de Menem (Senen y Boseer, 1999), cuestión que ocurrió en 1992, cuando la CGT San Martín, más los elementos moderados de la CGT Azopardo se reunificaron. El resto de la CGT Azopardo formó la CTA. Mientras que en 1994, surge otra escisión dentro de la CGT, naciendo el Movimiento de los Trabajadores Argentino (MTA) (Da Silva, 2006: 357, Molteni, 1998, Murillo, 2001, Senen y Boeser, 1999).

La división de fondo, entre los distintos sectores sindicales, no solo se enfocó en la posición frente a las reformas impulsadas por Menem sino que también en las estrategias de acción 
que se debían adoptar. Los sindicatos ligados a la CGT se subordinaron frente el gobierno, ante el temor que éste le quitara sus recursos. Adoptaron una estrategia de supervivencia organizativa, la que se reflejó en el intento de la CGT, tras reunificarse en 1992, de colocar condicionamientos a las reformas impulsadas por Menem, obteniendo así, recursos políticos e industriales (Murillo, 1997: 429-430) y preservar las características tradicionales de las relaciones laborales argentinas (Novick, 2001).

La CTA, en tanto, optó por la resistencia a las reformas (Murillo, 1997: 429-430). Fundada formalmente en 1997, congrega a los trabajadores del Estado (ATE) y a la Confederación General de Trabajadores de la Educación (CTERA). Además de sindicatos, la CTA está formada por miembros individuales y ONG's. Cuenta con intelectuales afiliados, los que se juntan en centros de estudios. Intenta tener una visión abarcadora del mundo del trabajo que incluya el barrio, los desempleados, empleados precarios o subocupados. La MTA o CGT disidente tuvo las mismas orientaciones tradicionales de la CGT. No obstante, se mostró independiente del Partido Justicialista y tuvo un discurso contrario a las reformas neoliberales. Realizó varios paros de 12 y 24 horas y se ha movilizado, entre otras cosas, contra el FMI (Novick, 2001). El líder de la MTA, el camionero Hugo Moyano, actualmente está a cargo de la CGT.

Otro problema de los sindicatos ha sido el de la representatividad que tienen sobre los trabajadores. Durante la década de 1990 han enfrentado problemas de legitimidad entre la población. Según una encuesta, sin fecha, un 61,3\% tenía una opinión negativa de la CTG, un $37 \%$ de la CTA y un $36,6 \%$ de la MTA. Las razones de la mala imagen eran que un $72 \%$ de los trabajadores creía que los sindicatos no defendían sus intereses; que un 38\% consideraba que los sindicatos estaban más cerca del gobierno que de los trabajadores; que un $31 \%$ afirmaba que no solucionaban nada, el $16 \%$ decía que las elecciones internas no eran limpias. Otras causas de la imagen negativa de los sindicatos son que los ciudadanos pensaban que estaban más cerca de los empresarios que de los trabajadores (12\%), que el sindicalismo tradicional no servía en la economía moderna (9\%), que solo les interesaba hacer paros (6\%) o que en las elecciones sindicales no habían listas opositoras (5\%) (Molteni, 1998: 6768).

Sin embargo, los sindicatos cuentan en el marco normativo el monopolio de la representación en las relaciones laborales. Ello les permite, solicitar reivindicaciones, a nombre de los trabajadores, aun cuando se encuentren deslegitimados. La capacidad de influir, a pesar de la división, puede deberse a la habilidad de la CGT para utilizar su acceso a los espacios de decisión y de contar con representantes en las comisiones parlamentarias claves para la mantención de sus intereses. 
Antes de 1983, la fortaleza del sindicalismo argentino estuvo dada por su centralización organizacional, su densidad y unidad política, además de la concentración geográfica. Sin embargo, tras 1989, la unidad cesó, los sindicalizados y sujetos a negociación disminuyeron y la competencia de la CTA desafió el liderazgo de la CGT (Norman, 2001: 216).

A pesar de los cambios en las condiciones que lo hacían fuerte, el sindicalismo argentino ha logrado influir en los procesos de decisiones de políticas públicas en diversos temas. Estos éxitos se han sustentado en el hecho que el sindicalismo argentino cuenta con un recurso de vital importancia, como el acceso al decisor de políticas públicas, además de tener una pericia que le permite tener resultados, aun cuando no cuente con otros recursos, como la unidad sindical.

\subsection{La CGT y su tradición de contacto con el decisor}

La relación entre los sindicatos y el Estado argentino fue normada por el general Perón durante la década de 1940, cuando creó una institucionalidad que estableció un control estatal a los sindicatos. En su vida pre-peronista, los sindicatos ya se mostraban dispuestos a contactarse con el Estado. Por ejemplo, entre 1916 y 1922, algunas centrales pedían la intervención del Presidente Hipólito Irigoyen, en varios de los conflictos sindicales (Tamarin, 1985: 67-70).

A poco de su creación, ocurrida en 1930, la Confederación General de Trabajadores (CGT), adquiere una importancia política que le permitió acercarse a la Casa Rosada, apareciendo la figura del "dirigente gremial", especie de caudillo del movimiento obrero. Según Victor Alba (1964: 355) la relación establecida con el gobierno hizo que la CGT virara hacia posiciones conservadoras debido a que, a través de "visitas a personajes", podía obtener lo que, en otras circunstancias debería buscar mediante la movilización. Durante la década de 1990, la CGT aun se inhibía de movilizarse pues continuó teniendo recursos, como las relaciones políticas con las autoridades, que le permitieron obtener concesiones del gobierno (Murillo, 2001: 179).

Con la llegada de Juan Domingo Perón al Ministerio del Trabajo, la CGT se vio notificada de que debía hacer sus planteamientos con respeto, criterio, raciocinio, debiendo esperar que el Ministerio estudiara técnicamente las medidas a tomar, tratando de satisfacer las justas peticiones de los gremios. En esa época, la CGT se dividió en dos facciones (oportunistas y viejos sindicalistas), siendo la vieja tendencia clausurada por el gobierno (Alba, 1964).

Perón, lleva adelante la promulgación de la Ley de Asociaciones Profesionales, basada en igual legislación del Estado corporativo italiano. Ella le permitió controlar los sindicatos ya que éstos debían inscribirse en el Departamento Nacional del Trabajo (Zapata, 1993). 
Tras la caída de Perón, en 1955, el peronismo fue proscrito, siendo el sindicalismo el medio mediante el cual el movimiento político pudo subsistir. El gobierno de Aramburu persiguió a los dirigentes sindicales, los que se dedicaron a resistir la nueva situación (James, 1990). Ante un escenario sin gobiernos peronistas, que se mantuvo hasta 1973, la CGT no abandonó sus prácticas de tener contactos con los gobiernos, debido a que el sindicalismo argentino tiene una "larga tradición de diálogo" (Victor Hugo Guida, Director Nacional de Asociaciones Sindicales, Entrevista personal, 11/12/2006, Héctor Daniel Tristán, Encargado Capacitación Unión del Personal Civil de la Nación [UPCN], Entrevista personal, 12/12/06), lo que llevó a que, según Jorge Triaca - dirigente sindical y primer Ministro del Trabajo de Menem - se negociara "con quien fuera" (Senen y Bosoer, 1999: 52). En 1958, llega al poder el radical Arturo Frondizi. A pesar de ser antiperonista, logra el apoyo del sindicalismo, tras prometer llevar adelante elecciones en los sindicatos intervenidos por el gobierno anterior, además de fortalecer la negociación colectiva (James, 1990: 124-5).

Entre 1962 y 1966 toma el control del sindicalismo Augusto Vandor. Para James (1990: 230-231), el "vandorismo" representa la negociación y aceptación de las condiciones existentes. La intención de influir en las decisiones gubernamentales llevó a que ciertos grupos sindicales, incluso, intentaran tener contactos con dictaduras militares de corte antiperonista. En 1966 el general Juan Carlos Onganía tomó el poder. James (1990: 288) ha sugerido que el vandorismo habría apoyado tácitamente el golpe de Estado. A semanas de asumir el poder Onganía, Vandor firma el convenio del sector metalúrgico en la Casa Rosada. En 1976, existieron dos visiones en la CGT respecto a la dictadura militar. Un grupo se mostró participacionista, mientras otros fueron más combativos. Dentro de los márgenes aceptados por los militares, el sindicalismo presionó, gradualmente, para obtener concesiones a su demanda (Drake, 1996: 164).

Durante la década de 1980, el sindicalismo fue, paulatinamente, perdiendo la influencia política que tuvo en las décadas anteriores. Tras la vuelta a la democracia, el peronismo dejó de ser perseguido, pudiendo participar regularmente en elecciones competitivas. De esta forma, el sindicalismo ya no era la única posibilidad de actuación política del movimiento.

Además, los magros resultados electorales obtenidos en las elecciones de 1983, cuando el partido era controlado por los dirigentes de la CGT, trajeron una renovación dentro del peronismo, en la que la rama sindical del PJ perdió espacios de participación política. Se buscó limitar el poder del sindicalismo en el partido, transformando al justicialismo en un partido de carácter clientelar. Ello se pudo lograr gracias a que las relaciones entre sindicalismo y el Partido Justicialista (PJ) no estaban institucionalizadas. Así, se dejó de lado la tradición, 
impuesta por Perón, de que el sindicalismo ocupara un tercio de las lista electorales justicialistas (Levitsky, 2004).

El gobierno de Menem (1989-1999) llevó adelante políticas económicas que tenían como objetivo debilitar el poder de los sindicatos y reducir los costos relacionados con la contratación de trabajadores (Norman, 2001). Además, ya habiendo perdido el derecho - impuesto por el propio Perón, de ocupar un tercio de las listas electorales del justicialismo -, el número de diputados sindicales fue disminuyendo en el transcurso de la década.

Aun así, el sindicalismo no perdió su capacidad de tener acceso directo a los más altos niveles del gobierno. La CGT continuó teniendo reuniones, sobre temas de su interés, con el propio Presidente Menem (Senen y Bosoer, 1999). Actualmente, si bien no existen rutinas de reuniones, el contacto entre los gobiernos y los sindicatos "es casi normal". En esta lógica, un buen Ministro es quien logra tener interlocutores con los cuales dialogar (Héctor Palomino, Área Estudios, Ministerio de Trabajo, Empleo y Seguridad Social [Argentina], Entrevista personal, 12/12/06).

Cuando hay conflictos sectoriales, las reuniones entre dirigentes y autoridades, pueden llegar a ser diarias (Victor Hugo Guida, Director Nacional de Asociaciones Sindicales, Entrevista personal, 11/12/2006). Incluso, la CTA, que no tiene vínculos con el peronismo, se ha reunido con todos los Presidentes, desde Menem, a Kirschner, aunque con menos periodicidad que la CGT. Con los Ministros, las reuniones son más habituales, especialmente cuando asume alguien la cartera de Trabajo convoca a los sindicatos a explicar sus planes. Los contactos no se limitan al gobierno y también ocurren en las comisiones parlamentarias (Pedro Wasiejko, Secretario Adjunto CTA, Entrevista personal, 12/12/06). Con los Ministros se tratan temas de las áreas de la cartera, mientras que con el Presidente se firman convenios o se discutan temas "estrictamente nacionales, que tengan que ver con los trabajadores" (Héctor Daniel Tristán, Encargado Capacitación UPCN, Entrevista personal, 12/12/06).

\subsection{La pericia para obtener resultados}

La tradición de contactos con el decisor ha hecho al sindicalismo argentino más proclive a la negociación que a actitudes de carácter militante (Alba, 1964). Cuando ha preferido actuar, a través de huelgas o paros, ha sido contra gobiernos no peronistas. A partir del trabajo sobre cifras entregadas por Zapata (1993: 104-106), se aprecia que, tras la caída de Perón en 1955, durante el período siguiente aumentan las huelgas por año, pero se reducen los días perdidos. De la misma manera, durante la vuelta a la democracia, si bien se reduce el número de huelgas al año, en 1958, - quizás debido a la preeminencia del liderazgo del vandorismo y sus concepciones de realpolitik (James, 1990) - aumenta el número 
de días perdidos, llegando a promediar la cifra más alta, superior a los 2,5 millones por año. Es destacable que durante los períodos en que autoridades democráticas tuvieron políticas a favor de los trabajadores ${ }^{4}$, los días perdidos superaron el millón, a pesar de que se reducía el promedio anual de huelgas.

La capacidad de movilizarse le ha permitido al sindicalismo influir en temas de su interés. Por ejemplo, al discutirse una reforma de la legislación laboral, entre 1987 y 1988, los sindicatos fueron exitosos al lograr que no se cambiara el tipo de relaciones existentes con anterioridad a la dictadura, manteniéndose la matriz de relaciones establecida por Perón entre 1945 y 1953. Se mantuvo la "personería gremial" y la negociación colectiva y los sindicatos lograron la devolución de las obras sociales ${ }^{5}$ (Molteni, 1998).

Los sindicatos han visto mermar su posición dentro del justicialismo, durante el gobierno de Menem no controlaron el Ministerio de Trabajo y vieron cómo el número de parlamentarios sindicales disminuyó. Incluso, en las elecciones de 1999, los diputados sindicalistas electos de la lista de la Alianza fueron más que los de la justicialista (Palomino, 2000: 125).

Aun cuando cada vez tuvo menos parlamentarios, ellos fueron distribuidos estratégicamente en las comisiones parlamentarias de Trabajo y Previsión, lo que le permitió al sindicalismo

4 Un breve resumen de las políticas de los gobiernos hacia los trabajadores argentinos se encuentra en Smith y Skidmore (1984)

5 Para poder representar los intereses de sus afiliados, es decir, ejercer funciones sindicales, se debe contar con la personería gremial. Esta se le otorga a un sindicato con más de seis meses de antigüedad en el registro y que cuente con, al menos, un $20 \%$ de los trabajadores de la rama. De existir más de una asociación, la personería gremial es entregada al sindicato que cuente con el mayor número de afiliados cotizantes sobre la cantidad promedio de trabajadores a representar. Un nuevo sindicato puede quitarle la personería jurídica a otro si demuestra, durante los primeros seis meses de su inscripción, que cuenta con un mayor número de cotizantes. Este monopolio se extiende al momento de elegir delegados de la asociación. Pueden participar todos aquellos afiliados al sindicato convocante. Es decir, se aumenta el monopolio del sindicato o la asociación con personería gremial. Molteni señala que en los procesos eleccionarios no es extraña la aparición de listas únicas. Las negociaciones colectivas fueron establecidas por normativa de 1944 y 1946. En ellas, la conciliación tenía carácter obligatorio, siendo el Estado un árbitro entre los empleadores y trabajadores. En 1953 se le entrega mayor independencia a empleadores y trabajadores para entenderse entre ellos, no obstante, se mantiene un requisito, de 1944, de que los acuerdos debían ser homologados administrativamente para tener efecto. La nueva legislación laboral de 1988 se basa en esta legislación. El Estado puede homologar o no los acuerdos, no existiendo recursos contra el rechazo al convenio. Los acuerdos tomados son válidos incluso para aquellos que no pertenecen al sindicato o asociación, tanto sindical como empresarial, que tiene el monopolio de su representación. Esto acuerdos son tomados en base una "generalidad" de la rama. Ello genera que PYMES con estructuras de costos distintas a empresas mayores, deban someterse a dichos acuerdos. Además, la legislación instaura el principio de ultraactividad. Con él, los convenios se mantienen vigentes aun después de vender el periodo por el cuál el convenio fue celebrado.

Negociadas entre los cincuenta y los sesenta, las obras sociales financiadas por empleadores y trabajadores, conformaban una serie de servicios de salud, más otro tipo de beneficios, como vacaciones, para los trabajadores sindicalizados. En 1976 se traspasó su administración desde los sindicatos a un Instituto Nacional de Obras Sociales. En 1988, debido a las presiones, Alfonsín se vio obligado a devolverlas a los sindicatos (Molteni, 1998). 
tener la posibilidad de bloquear proyectos del gobierno ${ }^{6}$. (Da Silva, 2006, Etchemedy y Palermo, 1998, Norman, 2001). La Comisión de Trabajo, en la Cámara de Diputados, se convirtió en el instrumento con el cual la CGT negaba o modificaba las iniciativas de Menem7. El sindicalismo ocupaban un importante porcentaje de la conformación de esta comisión, nunca inferior al 33\% en toda la década de 1990 (Norman, 2001: 26, 124).

En materia laboral, Menem tuvo una menor capacidad de aprobar proyectos que en el paquete de privatizaciones que llevó adelante. Los proyectos en asuntos laborales, además, se demoraron más tiempo en ser discutidos y solo fueron aprobados una vez que el gobierno optó por establecer mesas de trabajos, con sindicatos y empresarios, para consensuar las reformas (Etchemedy y Palermo, 1998, 564, 570, 576-567).

\section{La reforma previsional. De la reforma deseada a la reforma posible}

El gobierno de Menem impulsó una reforma a la previsión social, que entró en vigencia en el mes de julio de 1994. La ley 24.241, estableció un sistema de previsión mixto, al que se bautizó con el nombre de "Sistema Integrado de Jubilaciones y Pensiones" (SIJP). Está compuesto por un actor público - la Administración Nacional de Seguridad Social (ANSES) - y otros privados - las Administradoras de Fondos de Jubilaciones y Pensiones (AFJP), de capitalización individual.

El sistema, obligatorio para todos los asalariados mayores de 18 años, salvo los funcionarios de las Fuerzas Armadas, la policía y algunas categorías, divide las cotizaciones de los trabajadores de la siguiente manera: un $11 \%$ de su salario va al sistema público y un $7 \%$ al privado, más un adicional para invalidez, sobrevivencia y costos administrativos. Los independientes deben ingresar el $27 \%$ de las rentas imponibles. Por su parte, el empleador aporta un 10,88\% o 13,4\%, pudiendo llegar a un $21 \%$, en parte por seguros de desempleos. El Estado hace transferencias a través de impuestos específicos y cubre el déficit, de existir éste.

El sistema argentino distingue entre las prestaciones del pilar público y el privado. En el primero, los trabajadores pueden jubilar a los 65 (hombres) o 60 años (mujeres), teniendo 30 años de cotizaciones. A esta pensión se la llama Prestación Universal Básica (PUB) y corresponde a 2,5 MOPRE - es una medida idexada que se calcula cada año. Por ejemplo,

6 El sindicalismo perdió capacidad de influencia. Por ejemplo, durante 1993, la dirigencia de la CGT logró que, solamente, 6 de los 10 diputados sindicales votaran en la línea de la central. Ello se puede explicar por el hecho de que los diputados, una vez electos, comenzaron a actuar como políticos, con redes de clientes, y no como sindicalistas (Levitsky, 2004: 20-23).

7 Los proyectos del gobierno debían ser aprobados por las comisiones del parlamento antes de llegar a votaciones. 
para 2003 fue de $\$ 80$ argentinos. Además, el pilar público incorpora otro tipo de prestaciones como la Compensatoria y la Adicional por Permanencia En el pilar privado, se exigen los mismos requisitos para jubilar que en el público, siendo la pensión conformada por los aportes del afiliado más los intereses obtenidos (Castiglioni, 2005: 184-5).

La reforma previsional no se pudo realizar durante la década de 1980 por el rechazo de sindicatos y asociaciones de pensionados. Menem, si logró aprobar la reforma, con el apoyo de la CGT. La discusión política duró 18 meses. En ella participaron parlamentarios, sindicatos y pensionados, los últimos, movilizados desde 1992. La reforma aprobada fue distinta al proyecto, inicialmente, propuesto por el gobierno (Mesa-Lago, 1999: 140).

El gobierno intentó establecer un nuevo sistema de pensiones, con actores públicos y privados, el que no le reconocía los aportes a los menores de 40 años y los obligaba a entrar a un sistema privado de capitalización individual. Se intentó traspasar la previsión al sector privado, siguiendo la reforma chilena. La CGT se opuso y amenazó con la realización de una huelga general. Las críticas al proyecto eran que se estaba desvinculando el sistema previsional del concepto de seguridad social; que no existían estudios previos sobre los costos del cambio de sistema; que no se reconocían las imposiciones del sistema antiguo y; que no se le asignaban al Estado capacidades reguladoras (Da Silva, 2006: 349-350).

El gobierno cambió el proyecto, haciendo del sistema privado solo una opción, creó una AFJP estatal, permitió a los sindicatos crear sus propios fondos de pensiones y fijó prestaciones compensatorias para los afiliados y subsidios. La CTA se opuso a la nueva ley y recomendó a sus miembros mantenerse en el sistema público Con posterioridad, la central ha intentado la vuelta del sistema público ${ }^{8}$ (Da Silva, 2006: 348, Mesa-Lago, 1999: 140, Murillo, 2001 : 143-144, 151).

Matsushita (1999) plantea que el gobierno de Menem, al negociar con el sindicalismo, usó una estrategia de "paquete". Con ello hace referencia a que la autoridad presentaba una serie de proyectos de ley, siendo discutidos simultáneamente. Esta estrategia buscaba que el sindicato recibiera ciertas concesiones a cambio del apoyo a cuestiones que interesaban al gobierno. La reforma previsional, por ejemplo, fue discutida al mismo tiempo que los proyectos laborales y de liberalización de las obras sociales.

8 Con posterioridad, la central ha intentado la vuelta del sistema público. Esta lucha se ha realizado "desde fuera", pues el Gobierno no la convoca para discutir estos temas. Entre las acciones realizadas por CTA se cuenta un proyecto de diputados afines, que busca eliminar el sistema, una querella en la Corte Interamericana de Derechos Humanos y la realización de Jornadas Nacionales por la Nacionalización de la Previsión (Matías Cremonte, Encargado Jurídico Asociación de Trabajadores del Estado [ATE], Entrevista personal, 12/12/06). 
En un inicio, la CGT rechazó el proyecto de reforma previsional, aunque no contaba con una opción alternativa a la propuesta de Menem. La bancada sindical se alió con la oposición, principalmente la Unión Cívica Radical, para rechazar el proyecto enviado al Congreso. A la vez, la central aumento el nivel de las movilizaciones en contra de la política económica del gobierno. El $1^{\circ}$ de junio de 1992, la CGT realiza el primer paro contra el gobierno de Menem (Da Silva, 2006: 352).

El Presidente negoció con la CGT, ofreciéndole crear una comisión para estudiar la reforma de las obras sociales, pagar las deudas de ese sistema y convocar un "Consejo del Salario, la Productividad y el Empleo". A cambio, el gobierno pidió que la CGT apoyara la reforma previsional y se comprometiera a no ejercer medidas de fuerza durante los siguientes tres años. La CGT rechazó la propuesta y amenazó con nuevas movilizaciones, provocando un relajamiento de la posición del gobierno, el que se comprometió a revisar el decreto de reajuste de sueldos ${ }^{9}$, devolver a los sindicatos los recursos de las obras sociales, sanear las deudas de ese sistema, aprobar el Consejo recién mencionado, reconocer los aportes previsionales hechos al sistema previsional anterior a la reforma y hacer que el traspaso de los menores de 45 años, desde el sistema público de previsión a uno privado, fuera voluntario (Da Silva, 2006: 353).

Cuando el gobierno se sentó a discutir con la CGT, ésta ya tenía un proyecto sobre la reforma previsional que deseaba. Los principales puntos de la reforma propuesta por el sindicalismo peronista eran, en primer lugar, ampliar el tipo de organizaciones que podían constituir Asociaciones de Fondos de Jubilaciones y Pensiones ${ }^{10}$ (AFJP) y, en segunda instancia, hacer que el sistema privado de capitalización individual fuese voluntario (Da Silva, 2006: 359).

Dos semanas después de que la CGT presentara sus propuestas previsionales, firmó un acuerdo con el gobierno sobre la materia, en noviembre de 1992, el que se convirtió en ley (Da Silva, 2006: 359)

9 Menem cambió la forma de reajuste de los sueldos de los trabajadores, reemplazando la indexación de éstos por readecuaciones en base a los aumentos en productividad de las empresas (Norman, 2001) 10 El primer punto puede ser entendido, por una parte, como una arista de la estrategia de "supervivencia organizacional" que la CGT impulsó en la década de 1990 (Murillo, 1997). Los sindicatos se incorporaron, así, a las AFJP como un "sindicalismo de negocios", lo que convirtió a sus bases en una población cautiva a la cuál se le podían vender servicios (Palomino, 2000: 126). Sin embargo, esto no era una novedad, ya que los sindicatos, desde antes, han sido prestadores de servicios a través de las obras sociales (Novick, 2001). 
TABLA 3: La reforma previsional. El Proyecto de Menem y la postura de la CGT

\begin{tabular}{|c|c|c|}
\hline Proyecto original Menem & Proyecto CGT & Acuerdo Gobierno-CGT \\
\hline $\begin{array}{l}\text { Propone la creación de un } \\
\text { nuevo sistema previsional de } \\
\text { capitalización individual, } \\
\text { creánd o se fond os } \\
\text { administrados por AFJP's, } \\
\text { parecido al implementado en } \\
\text { Chile en } 1981 \text {. } \\
\text { Los trabajadores mayores de } \\
40 \text { seguirían en el sistema } \\
\text { público. } \\
\text { Los menores de } 40 \text { años } \\
\text { d e b í a n p a s a r, } \\
\text { obligatoriamente, al sistema } \\
\text { privado. } \\
\text { A los trabajadores que } \\
\text { debían incorporarse al } \\
\text { sistema privado, no se les } \\
\text { reconocerían los aportes } \\
\text { previsionales. }\end{array}$ & $\begin{array}{l}\text { Mantener la estructura del régimen } \\
\text { previsional público, siendo el privado } \\
\text { voluntario y suplementario. } \\
\text { Permitir que instituciones sin fines } \\
\text { de lucro, como sindicatos y otras, } \\
\text { como fondos mutuos o } \\
\text { cooperativas, tengan AFJP's. } \\
\text { Diferenciar aportes del fondo } \\
\text { público de los privados. } \\
\text { Trabajadores deben poder optar } \\
\text { entre más de un tipo de } \\
\text { capitalización privada. } \\
\text { Aseguramiento de pensiones } \\
\text { mínimas garantizadas. } \\
\text { Creación de incentivos para que } \\
\text { empleadores aporten a los } \\
\text { programas contributivos a favor de } \\
\text { los trabajadores. } \\
\text { Los agentes del sistema privado, } \\
\text { que no sean AFJP's deben ser } \\
\text { reguladors por organismos legales. }\end{array}$ & $\begin{array}{l}\text { Se permite que instituciones, distintas } \\
\text { a las sociedades anónimas, tengan } \\
\text { AFJP's. Todas estas instituciones quedan } \\
\text { sujetas a las normas legales del Sistema } \\
\text { Integrado de Jubilaciones y Pensiones } \\
\text { Se prohíbe condicionar beneficios a la } \\
\text { afiliación a determinadas AFJP's. } \\
\text { Garantiza la participación de los } \\
\text { beneficiarios a través de un organismo } \\
\text { que asegure la fiscalización y regulación } \\
\text { del sistema. } \\
\text { Asegura que las rentas vitalicias se } \\
\text { ajustarán a las normas fijadas por la } \\
\text { Superintendencia de Seguros y la de } \\
\text { AFJP's. } \\
\text { Profundiza definiciones relacionadas } \\
\text { con las pensiones de invalidez. } \\
\text { Define el concepto de remuneración, } \\
\text { para dejar fuera los beneficios sociales. } \\
\text { Evita la doble tributación entre la AFJP } \\
\text { y las aseguradoras. }\end{array}$ \\
\hline
\end{tabular}

Fuente: Da Silva (2006: 348, 358-361) Mesa-Lago (1999: 140) y Murillo (2001: 143-144, 151).

A pesar de este acuerdo, quedaban cosas por definir en la discusión parlamentaria, como la obligatoriedad del traspaso al sistema privado. Durante 1993, los grupos moderados, fueron reemplazados de la dirección de la CGT por otros sectores más críticos de las políticas económicas de Menem. Con esta nueva dirección, la central logró que el gobierno se abstuviera de hacer obligatorio el traspaso previsional a prestadoras privadas. Tras cuatro intentos fallidos, durante 1993 Menem logró el quórum para hacer que su proyecto de reforma previsional fuera discutido en la sala de la Cámara de Diputados (Da Silva, 2006: 366-368).

La cercanía de las elecciones presidenciales provocó un acercamiento entre la CGT y el gobierno de Menem. De los 18 diputados sindicalistas, 13 debían ir a la reelección en diciembre de 1993 (Da Silva, 2006: 364). El sindicalismo peronista buscó acercarse a Menem, para obtener cupos en las listas parlamentarias del PJ. En tanto, el Presidente buscaba reformar la constitución para poder intentar su reelección, por lo que necesitaba apoyo político. Ello lo llevó a acercarse al sindicalismo. Incluso, durante su campaña presidencial, asistió, junto al Ministro de Economía, Domingo Cavallo, a sedes sindicales (Senen y Bosoer, 1999).

Al igual que en las políticas laborales, el sindicalismo fue efectivo en paralizar el proyecto de Menem para, con posterioridad, ser parte de la discusión y formulación de la reforma 
previsional que entró en vigencia en 1994. Al igual que en lo relativo a la reforma laboral, Menem no pudo imponer la reforma que él, y su equipo económico deseaba. Al contrario, la reforma que se aprobó fue una "reforma posible" (Etchemedy, 2001) que en lugar de ser privatizadora, como esperaba el Presidente, fue uno de los cambios previsionales con los mayores niveles de mantenimiento de características públicas (Mesa-Lago, 1999: 136).

Menem intentó sacar ventajas a través de una estrategia de "paquete", pero ella no aseguró que él fuera quien obtuviera las mejores resultados. El gobierno, al negociar la reforma previsional con la CGT debió entregarle concesiones endógenas (propias del sistema previsional) como exógenas (como los cambios del decreto de productividad y en el sistema de obras sociales) (Da Silva, 2006: 370). En el balance final, si bien logró reformar la previsión, este cambio fue distinto del que se esperaba implementar.

\section{Conclusiones}

En esta nota de investigación se ha intentado dar un marco explicativo sobre la capacidad del sindicalismo argentino para influir en el tipo de reforma previsional llevada adelante por el gobierno de Carlos Menem. Como se ha venido argumentando, las reformas económicas ocurridas en Argentina fueron fruto de un proceso de negociación y construcción de coaliciones, por parte de actores políticos y sociales. Entre éstos, el sindicalismo ha ocupado un lugar especial.

La CGT ha podido tener éxitos en las discusiones de políticas laborales y previsionales, aun cuando la década de 1990 mostró a una central que perdía espacios de poder en el PJ y el Congreso de la Nación. Hemos propuesto que los resultados sindicales se explican por los recursos políticos con que la CGT ha contado y por la pericia que ha mostrado para utilizarlos.

La CGT cuenta con varios recursos de importancia. En primer lugar, gracias a la legislación laboral peronista, los sindicatos argentinos tienen asegurado el monopolio de la representación de los trabajadores, lo que les permite negociar, sin importar su tamaño y que la ciudadanía tenga una serie de reparos sobre su actuación y representatividad (Molteni, 1998). Si bien no son fundamentales para negociar, la dimensión sindical y la representatividad, además de la unidad organizativa, pueden ser recursos de importancia a la hora de movilizar al sindicalismo, especialmente cuando el peronismo se encuentra en la oposición política - como ocurrió en la década de 1980, durante el gobierno del radical Raúl Alfonsin - .

En segundo lugar, el sindicalismo argentino tiene una importante posición dentro del sistema político. La CGT fue una base de apoyo de Perón y su movimiento justicialista, durante 
su primer mandato. Su poder político dentro del PJ fue asegurado, con la entrega, por parte del general, de un tercio de las listas electorales. En la década de 1990 la tenencia de parlamentarios en comisiones parlamentarias claves fue fundamental para asegurar un lugar central a la CGT en la discusión de políticas.

Cuando el peronismo estuvo proscrito, el sindicalismo consolidó su posición dentro del movimiento, al ser su único medio de actuación (James, 1990). De esta forma, se ha consolidado una relación entre el PJ y la CGT que dificulta que un gobierno peronista no tome en cuenta las opiniones de la central, aunque ello no quiere decir que la central tenga control sobre la agenda de los gobiernos.

Junto a las relaciones políticas que tiene con el justicialismo, la CGT tiene un acceso al decisor, peronista o no, que data de la década de 1930 (Alba, 1964), cuestión que le permite negociar temas que son de su interés. Desde esa época, ha mostrado tener una pericia para movilizar sus recursos políticos de manera exitosa, para negociar con la autoridad.

La CGT no ve comprometida sus opciones de acceder a las instancias de decisión estatal si existen gobiernos nacionales no peronistas. Cuando ello ocurre, acceden a los decisores, preferentemente, a través de la movilización sindical. A modo de ejemplo, en 1958 y 1988 logró que gobiernos radicales volvieran la legislación laboral que levantó Perón en su primer gobierno y que había sido alterada por dictaduras militares (James, 1990, Molteni, 1998).

La posibilidad de tener participación en los espacios de decisión se ve reforzada por la pericia del sindicalismo argentino para bloquear políticas y reformas, o vetar partes de éstas. Esto hace que, para que los cambios políticos, en temas relacionados al mundo del trabajo, sean viables, se deba llegar a acuerdos con la central.

En el caso de la reforma previsional, la forma en que la CGT utilizó sus recursos, y las estrategias de acción que implementó, le permitieron superar el escenario adverso con el que se iniciaba la discusión para transformarlo en otro que abría mayores posibilidades para participar en la discusión de la política previsional que se iba a implementar.

En un inicio, la CGT tuvo una actitud negativa hacia la participación en la formulación de la política previsional. La central fue exitosa en articular una resistencia visible al proyecto de Menem, a través de la huelga del $1^{\circ}$ de junio de 1992 y el voto de sus diputados sindicales en la Comisión de Previsión. La central, en ese año, había recuperado su unidad organizativa, lo que fortaleció su capacidad de movilización.

La CGT utilizó a su favor el efecto que provocaba que el sindicalismo le hiciera una huelga a un Presidente peronista, manifestándose en contra de una propuesta que limitaba los 
derechos de seguridad social a los trabajadores. Con la paralización del proyecto, el gobierno se dio cuenta que no sería capaz de impulsar la reforma sin el concurso sindical. Por ello, quizás, se inhibió, al igual que en las políticas laborales (Norman, 2001), de aprobar cambios vía decreto, como si lo hizo en otras materias.

En esta primera fase de la formulación de la reforma, la CGT tuvo la capacidad de constituirse en un actor con capacidad de veto, aun cuando no tenía un proyecto alternativo, que logró inhibir al gobierno de seguir en su intento de hacer el sistema de capitalización individual obligatorio. Una vez que obtuvo el resultado esperado, la central recurrió a sus relaciones con el partido para mostrarse leal con el gobierno y comprometiéndose a apoyar la reforma, pero con concesiones. Las relación partidaria no fue la única razón que permitió el contacto, pues la CGT tiene la capacidad de contactar al decisor, aun cuando no sea peronista, pero si ayudó a que las partes se interesaran en llegar a acuerdos.

La CGT logró cambiar el escenario en el cuál la reforma previsional iba a ser discutida. Su inicial actitud negativa a la participación provocó que el gobierno modificara su actitud. Al igual que en la discusión sobre los proyectos de legislación laboral, en la discusión previsional la reforma lograda se construyó en base a una negociación. Así, la central tuvo una actitud positiva frente a la participación en la formulación de la política. Sin embargo, éste no fue el único recurso que permitió el acercamiento. Menem quería ser reelegido y, para ello, requería del apoyo de la CGT, que jugaba un importante lugar como base de apoyo político dentro del peronismo.

A petición de Menem, el mismo Ministro de Hacienda, Domingo Cavallo, se reunió con la central, para hacerle dos propuestas de acuerdo (Da Silva, 2006: 353). Al igual que cuando resistió el proyecto, al discutir la reforma, la CGT mostró tener capacidad de veto en la formulación del proyecto. Cuando levantó una propuesta, logró que sus dos principales intereses (la no obligatoriedad del sistema privado y la posibilidad de crear sus propias AFJP's) fueran aceptados por el gobierno, a cambio del apoyo del cambio del sistema vigente.

El sindicalismo peronista fue capaz de acordar una reforma con el gobierno que incorporaba, preferentemente, sus intereses. En primer término, logró que, junto a sociedades anónimas, otros actores fueran autorizados para tener AFJP's. Así, pudo hacer que su interés primara al de las empresas privadas. En segundo lugar, el hecho que el gobierno firmara un acuerdo solo con la CGT, y no con asociaciones empresariales, por ejemplo, grafica el rol principal que el sindicalismo peronista tuvo en la formulación de la reforma.

El caso presentado muestra cómo la tenencia y la forma en que los recursos políticos son utilizados tienen efectos en los niveles de influencia que los actores políticos tienen sobre las 
decisiones de la autoridad, tal como lo sugiere Dahl (1985). Las interpretaciones sobre la actuación de la CGT tienden a destacar esta cuestión, además de recalcar la tradición negociadora de la central. Sin embargo, no existe mayor literatura sobre cómo la central construyó la pericia para usar sus recursos. Esta cuestión debiera ser tratada por estudios posteriores, debido al papel central que esta cualidad tiene en la acción y los resultados del sindicalismo peronista.

En especial, la investigación debiera intentar responder dos cuestiones. En primer lugar, si la CGT tiene una tradición de acceso al decisor, es necesario entender cómo los dirigentes desarrollaron la pericia para lograr contactar y negociar con la autoridad y de qué manera elaboran estrategias para lograrlo. En segundo lugar, sería interesante entender cómo esas capacidades, que datan de 1930, han logrado transmitirse entre las distintas dirigencias que han existido desde esa época. Especial atención se debiera colocar en conocer cómo estos dirigentes han sido socializados dentro de las organizaciones sindicales, quiénes los han formado como líderes y qué han intentado enseñarles.

\section{Referencias bibliográficas:}

Alba, Victor. 1964. Historia del Movimiento Obrero en América Latina. México: Libreros Mexicanos Unidos.

Armijo, Leslie y Philippe Faucher. 2002. "We Have a Consensus": Explaining Political Support for Market Reforms in Latin America. Latin American Politics and Society 44 (2): 1-40.

Barría, Jorge. 1971. Historia de la CUT. Santiago: Prensa Latinoamericana. BID - Banco Interamericano del Desarrollo. 2006. La Política de las Políticas Públicas. Progreso Económico y Social en América Latina. Washington: BIDDavid Rockefeller Center for Latin American Studies, Harvard University. Castiglioni, Rossana. 2001. The Politics of Retrenchment: The Quandaries of Social Protection under Rule in Chile, 1973-1990. Latin American Politics and Society 43 (4): 37-66.

2005. Reforma de Pensiones en América Latina: Orígenes y Estrategias, 1980-2002. Revista de Ciencia Política 25 (2): 173-189. Coelho, Vera. 2002. El Poder Ejecutivo y la Reforma de la Seguridad Social: Los Casos de la Argentina, Brasil y Uruguay. Desarrollo Económico 42 (165): 45-62. Cremonte, Matías. 2006. Encargado Jurídico Asociación de Trabajadores del Estado, Entrevista personal, 12 de diciembre.

Da Silva, Jara. 2006. Executivo, Legislativo e Sindicatos na Reforma Previdenciária Argentina. Dados 49 (2): 345-377.

Dahl, Robert. 1985. Análisis Político Actual. Buenos Aires: EUDEBA. Deutsch, Karl. 1976. Política y Gobierno. México: Fondo de Cultura Económica. Drake, Paul. 1996. Labor Movements and Dictatorships. The Southern Cone in Comparative Perspectiva. Baltimore: The Johns Hopkins University Press. Etchemedy, Sebastían y Vicente Palermo. 1998. Conflicto y Concertación. Gobierno, Congreso y Organizaciones de Interés en la Reforma Laboral del Primer Gobierno de Menem (1989-1995). Desarrollo Económico 37 (148): 559-590. 
Etchemedy, Sebastián. 2001. Construir Coaliciones Reformistas: La Política de las Compensaciones en el Camino Argentino Hacia la Liberalización Económica. Desarrollo Económico 40 (160): 675-706.

Guida, Víctor Hugo. 2006. Director Nacional de Asociaciones Sindicales, Entrevista personal. 11 de diciembre.

James, Daniel. 1990. Resistencia e Integración. El Peronismo y la Clase Trabajadora Argentina, 1946-1976. Buenos Aires: Editorial Sudamericana.

Levitsky, Steven. 2004. Del Sindicalismo al Clientelismo. La Transformación de los Vínculos Partido-Sindicatos en el Peronismo, 1983-1999. Desarrollo Económico 44 (173): 3-32.

Madrid, Raúl. 2005. Ideas, Economic Pressures and Pension Privatization. Latin American Politics and Society 47 (2): 23-50.

Matsushita, Hiroshi. 1999. El Sindicalismo en Tiempos de Menem de Senen Santiago y Fabián Bosoer, 165-193. Buenos Aires: Corregidor.

Mesa-Lago, Carmelo. 1999. Política y Reforma de la Seguridad Social en América Latina. Nueva Sociedad 160: 133-150.

2001. Structural Reform of Social Security Pensions in Latin

America: Models, Characteristics, Results and Conclusions. International Social Security Review 54 (4): 67-92.

Margarita Molteni. 1998. La transformación económica de la Argentina y el movimiento sindical. En El sindicalismo ante los procesos de cambio económico y social en América Latina editado por Fundación Konrad Adenauer. Buenos Aires: CIEDLA.

Murillo, Victoria. 1997. La Adaptación del Sindicalismo Argentino a las Reformas de Mercado en la Primera Presidencia de Menem. Desarrollo Económico 37 (147): 419-446.

2000. Del Populismo al Neoliberalismo: Sindicatos y Reformas de Mercado en América Latina. Desarrollo Económico 40 (158): 179-212. 2001. Labor Unions, Partisan Coalitions and Market Reforms in Latin America. Cambridge: Cambridge University Press.

Norman, Richard. 2001. Democratizing the Political Economy: The ExecutiveBusiness Coalition and Labor Reform in Argentina, 1989-1998, Tesis de Doctorado, University of Boston.

Novick, Marta. 2001. Nuevas reglas del juego en Argentina, competitividad y actores sindicales. En, Los sindicatos frente a los procesos de transición política compilado por De la Garza Toledo, Enrique. Buenos Aires: CLACSO. Palomino, Héctor. 2000. Los Sindicatos en la Argentina Contemporánea. Nueva Sociedad 169: 121-134.

2006. Área Estudios, Ministerio de Trabajo, Empleo y Seguridad Social, Entrevista personal, 12 de diciembre.

Pasquino, Gianfranco. 1989. Participación Política, Grupos y Moviimentos. En Manual de Ciencia Política, compilado por Pasquino, Gianfranco, 179-215. Madrid: Alianza Editorial.

Senen, Santiago y Fabián Bosoer. 1999. El Sindicalismo en Tiempos de Menem. Buenos Aires: Corregidor.

Skidmore, Thomas y Peter Smith. 1984. Modern Latin America. New York: Oxford University Press.

Tamarin, David. 1985. The Argentine Labor Movement, 1930-1945. A Study in the Origins of Peronism. Alburquerque: University of New Mexico. 
Tristán, Héctor Daniel. 2006. Encargado Capacitación Unión del Personal Civil de la Nación, Entrevista personal. 12 de diciembre.

Tsebilis, George. 1995. Decision Making in Political Systems: Veto Players in Presidentialism, Parliamentarism, Multicameralism and Multipartydism. British Journal of Political Science 25 (3): 289-325.

1999. Veto Players and Law Production in Parliamentary

Democracies: An Empirical Analysis. The American Political Science Review 93(3): 591-608.

Valenzuela, J. Samuel. 1991. Labor Movements and Political Systems: A Conceptual and Typological Analysis. Working Paper 163 December. The Helen Kellog Institute fot International Studies, University of Notre Dame.

Wasiejko, Pedro. 2006. Secretario Adjunto Central de Trabajadores Argentina, Entrevista personal, 12 de diciembre.

Weyland, Kurt. 2006. External Pressures and Internacional Norms in Latin American Pensions Reform. Working Paper 323 Febraury. The Helen Kellog Institute fot International Studies, University of Notre Dame.

Zapata, Francisco. 1993. Autonomía y Subordinación en el Sindicalismo Latinoamericano. México: El Colegio de México - Fondo de Cultura Económica.

Eduardo Araya Moreno

Administrador Público y Magíster en Ciencia Política de la Universidad de Chile. Doctorando en Sociedad de la Información en la Universidad Oberta de Catalunya. Es Profesor Asistente y Director del Departamento de Gobierno y Gestión Pública del Instituto de Asuntos Públicos de la Universidad de Chile. Su investigación actual se central en uso de Internet por parte de los partidos políticos en América Latina y en la capacidad regulatoria del Estado Chileno. Autor de La Toma de Decisiones Políticas. La Experiencia del Sector Salud (Santiago: OPS, 1995). Ha publicado artículos en revistas como Anuario de la Universidad de Chile y Journal of Public Affairs Education.

E-mail: earayam@uchile.cl

\section{Diego Barría Traverso}

Administrador Público de la Universidad de Chile. Tesista del Programa de Historia de la Pontificia Universidad Católica de Chile. Sus principales temas de interés se centran en las reformas administrativas y a la vida y profesionalización de los empleados públicos durante las últimas décadas del siglo XIX en Chile. Actualmente se desempeña como investigador del proyecto "La influencia de los sindicatos en las políticas públicas en América Latina", financiado por el Departamento de Gobierno y Gestión Pública, INAP, Universidad de Chile y la Confederación Francesa Democrática de Trabajadores.

E-mail: dbarria@uchile.cl

\section{Oscar Drouillas Carrasco}

Administrador Público de la Universidad de Chile. Se ha desempeñado como consultor en el Proyecto del Banco Interamericano de Desarrollo sobre modernización del Parlamento Chileno. Actualmente se desempeña en Capacita. Ha impartido docencia en la Universidad Mayor y el Instituto Nacional del Fútbol. Actualmente dicta cátedras en la Universidad de Chile. Sus principales temas de interés se refieren al diseño organizacional y el uso de instrumentos de gestión.

E-mail: odrouillas@vtr.net 